\title{
Museu Paulista da USP: percursos e desafios
}

\author{
Cecília Helena De SALLES Oliveira
}

Os museus continuam a constituir modelos tanto para estudar as tensões e negociações em curso na comunidade científica como as que ocorrem entre esta e a sociedade contemporânea, quer do ponto de vista da história das ciências quer das instituições culturais.

(Michel Van Praët, 2009)

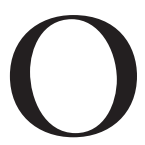

OBJETIVO deste artigo é propor alguns questionamentos a respeito da posição atual dos museus de História no âmbito da pesquisa, produção e divulgação de conhecimentos, tomando como referência o Museu Paulista, integrado à Universidade de São Paulo há quase 50 anos. Tanto o título quanto a epígrafe escolhidos sugerem que o ponto de partida de minhas considerações é o reconhecimento de que os museus, ao longo de sua história, vêm atuando num universo de forças políticas, protagonizado por diversos agentes que partilham com eles intenso debate em torno da ciência e da cultura. Sujeito e objeto de disputas em torno do passado e de seus usos, o Museu encontra-se em contínuo movimento de legitimação e reflexão, o que transparece em sua trajetória. Por sua vez, situar o Museu entre lugar de geração de conhecimentos inovadores e "lugar de memória" representa interpretá-lo como local no qual se entrelaçam a preservação de patrimônios, o estudo e a abordagem de temas e questões específicos e as responsabilidades sociais que em nosso tempo podem ser exercidas por museus universitários.

\section{Museu Paulista: marcos de uma trajetória}

Incorporado à Universidade de São Paulo em 1963, o Museu dedica-se na atualidade ao campo de conhecimentos denominado História da Cultura Material, com ênfase nos estudos sobre a formação histórica da sociedade brasileira, em geral, e sobre a formação da sociedade paulista, em particular.

Trata-se de instituição científica e cultural centenária, cuja trajetória iniciou-se em 1893. Naquela ocasião, e em concomitância à organização do regime republicano, o Monumento - erguido pelo governo imperial na capital paulista nas proximidades do riacho do Ipiranga para celebrar a Independência e a fundação do Império - foi apropriado pelas autoridades do novo regime para abrigar coleções de história natural e de história nacional, dando origem ao primeiro museu público de São Paulo, oficialmente inaugurado em 7 de setembro de 1895. ${ }^{1} \mathrm{O}$ fato de o Museu estar sediado no Monumento do Ipiranga fez que, entre outras razões, se tornasse popularmente conhecido como Museu do Ipiranga. 
Ao longo dos anos, o caráter inicialmente conferido ao Museu tornouse mais complexo e passou por modificações em razão de conjunto amplo de circunstâncias, dentre as quais pode-se mencionar a maior especialização das disciplinas e áreas do saber, bem como o surgimento de demandas sociais e políticas, articuladas à história/memória nacional, diversas das que existiam nos fins do século XIX. Isso representou a organização e ampliação de coleções de objetos, iconografia e registros textuais relacionados a políticos do Império, aos primeiros presidentes da República e a aspectos daquilo que se denominava "civilização brasileira", com o gradual predomínio da História, assim como de estudos arqueológicos e antropológicos sobre as chamadas ciências da natureza (Bittencourt, 2010). Um dos marcos dessa transformação foi a década de 1920, quando se verificou uma reatualização do sentido celebrativo do prédio e do Museu, momento em que se comemorava o Centenário da Independência. Às reformas internas do edifício, naquela época, agregou-se a criação do Museu Republicano "Convenção de Itu", inaugurado em 1923, também concebido como memorial nacional.

Dessa maneira, e sob o patrocínio de políticos, intelectuais e empresários ligados ao Partido Republicano Paulista, entrelaçava-se a memória de dois episódios fundadores da nação - a proclamação da Independência e o desabrochar da campanha republicana em São Paulo, identificada à reunião de representantes da cafeicultura paulista, que ocorreu em abril de 1873, no sobrado da família Almeida Prado, na cidade de Itu (Souza, 2003 ). Projetavam-se, assim, por intermédio do uso de fragmentos do passado, o presente e o futuro de São Paulo, interpretado pelos grupos então no poder como solo original e mítico da gênese da nacionalidade brasileira.

As obras de decoração interna do Museu Paulista, que acabaram por consolidar as imagens com as quais a instituição se popularizou, foram iniciadas na década de 1920, mas sua realização prolongou-se pelas décadas seguintes. Em 1937, a parcela maior da decoração estava pronta, mas os últimos nichos na parede do edifício foram preenchidos apenas no início dos anos de 1960 (Anais do Museu Paulista, 2002-2003, p.10-1).

O conjunto decorativo ocupa os espaços previamente definidos no Monumento para a montagem de um panteão nacional, conforme proposto no Regimento da instituição de 1894. Em linhas gerais, projeta um panorama visual e grandioso da construção da história do Brasil, entre o século XVI e o início do $\mathrm{XX}$, da qual edifício e acervos seriam expressão material e simbólica. Da colonização em solo paulista, representada pelos retratos de Martim Afonso de Souza, Tibiriçá, D. João III e João Ramalho, alocados no saguão, envereda-se pelo período em que teria ocorrido a formação do território, representado pelas figuras de bandeirantes e por ânforas de cristal contendo águas de rios brasileiros, todos ornamentos da escadaria em mármore que leva ao piso superior da edificação. Ali, adentra-se, então, ao momento da Independência e confirmação da soberania do país, evocado por meio da escultura monumental de D. Pedro I e por retratos 


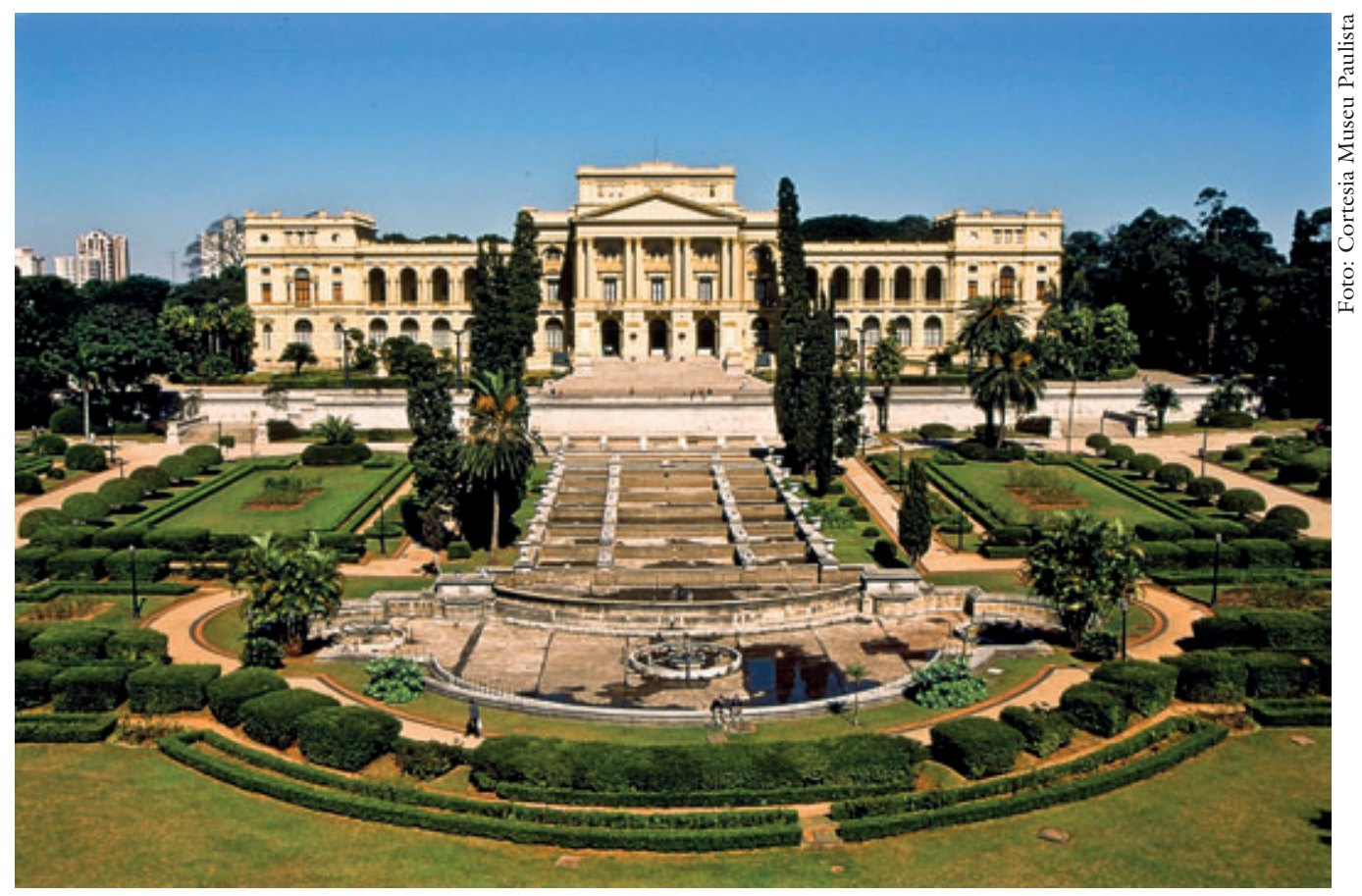

Fachada do Museu Paulista.

e registros nominais em bronze daquelas personagens consideradas, à época, os fundadores da nação, aos quais foram integradas as figuras de Dona Leopoldina, Maria Quitéria e Sóror Angélica (Taunay, 1937). Essa construção historiográfica pode ser considerada o desdobramento e a confirmação de implicações interpretativas criadas pelo painel confeccionado por Pedro Américo, entre 1886 e 1888. Idealizado especialmente para decorar o salão de honra do Monumento, ao longo do século XX veio a se tornar a representação emblemática do episódio conhecido como o "grito do Ipiranga” (Oliveira \& Valladão, 1999).

Esse direcionamento em relação a estudos referentes ao caráter da sociedade brasileira e à disciplina da História expunha a criação da nação brasileira em moldes diversos dos que as Ciências da Natureza poderiam ensejar. Tal delineamento coincidiu com a gestão de Afonso d'Escragnolle Taunay, entre 1917 e 1945, sendo reforçado com a transformação do Museu em Instituto complementar à Universidade de São Paulo, em 1934. No decreto de criação da Universidade, explicitava-se que o "Museu de Arqueologia, História e Etnografia que é o Museu Paulista” deveria concorrer, em conjunto com outros Institutos, a exemplo do Instituto Butantã e do Instituto Agronômico de Campinas, para ampliar o ensino e as ações da Universidade. Entretanto, somente entre 1939 e 1940, as coleções de Ciências da Natureza foram deslocadas do Museu Paulista para a formação de outras instituições, sublinhando-se entre elas o Museu de Zoologia. Posteriormente, na década de 1980, período em que foram dados novos passos para a integração do Museu aos ditames da Universidade, as áreas de estudo continuaram, ainda, direcionadas para Arqueologia, História e Etnologia. ${ }^{2}$ 
A partir da década de 1990, houve a redefinição das áreas de atuação do Museu Paulista com a eleição do campo da História da Cultura Material como eixo conceitual e metodológico tanto da produção científica quanto do ensino e das atividades de extensão. Nesse momento, as coleções arqueológicas, etnológicas e antropológicas foram deslocadas para o Museu de Arqueologia e Etnologia, também palco de profunda reorganização. ${ }^{3}$ Ao mesmo tempo, buscou-se maior integração à estrutura e aos procedimentos da Universidade, com a implantação da carreira docente nos Museus, em meio a outras medidas, processo que veio a se consolidar no momento atual com as modificações estatutárias votadas pelo Conselho Universitário, em 2010. ${ }^{4}$

Apesar de aqui apenas sumariados, é relevante acompanhar os marcos mais notórios da trajetória do Museu Paulista, pois revelam rupturas e continuidades institucionais, que exerceram influência decisiva na formação, estudo e extroversão dos patrimônios que o Museu abriga (e que continuam a crescer), em razão precisamente dos desafios colocados aos museus contemporâneos, de forma geral e, sobretudo, aos museus universitários. Nesse sentido, a definição do Museu como núcleo de pesquisas inovadoras em sua área não quer dizer que sejam desconsiderados os compromissos da instituição com o enorme público não especializado que o visita há mais de século. Por sua vez, não é possível esquecer os vínculos com o ensino universitário e com o desenvolvimento de atividades culturais e educacionais mais abrangentes, do mesmo modo como é intrínseco aos museus o papel de agentes conservadores dos patrimônios sob sua guarda (Meneses, 1994). É precisamente esse desejado entrelaçamento entre preservação de bens culturais, produção e socialização de conhecimentos que tem provocado o questionamento das tradições historiográficas e das representações do passado, inscritas naquele espaço, abrindo-se a possibilidade para reflexões e experiências referenciadas na abordagem crítica de temas e questões interdisciplinares, interrogando-se igualmente a história da instituição e os modos, por vezes erráticos, pelos quais seus acervos foram sendo constituídos.

\section{Memória e saber sobre a história}

Numa primeira aproximação, seria possível considerar o Museu Paulista como "lugar de memória", em virtude das injunções históricas do edifício e de parcela importante de suas coleções com o delineamento da memória nacional. "Lugar de memória", expressão que se tornou banalizada entre nós, foi noção criada por Pierre Nora (1984), na década de 1980, em meio ao debate que cercou o bicentenário da Revolução Francesa. Encontra-se ligada a uma avaliação extensiva dos fundamentos políticos e historiográficos que sustentaram a produção da história nacional na França e à investigação das possibilidades da escrita de uma outra história nacional no momento daquelas comemorações.

Ao utilizá-la, procuro, no entanto, seguir observações feitas por François Hartog à obra e aos esforços canalizados por Pierre Nora. Hartog (2003) apontou os vínculos entre o conceito "lugar de memória", a obra Les lieux de mémoi- 
res e aquilo que denominou "presentismo", uma relação específica com o tempo e o passado. O "presentismo" seria um regime de historicidade ${ }^{5}$ assinalado por uma "progressiva invasão do horizonte por um presente mais e mais ampliado [e] hipertrofiado", o que teria se tornado visível a partir dos anos 1970/1980. Para o Hartog (1996), a força motriz foi o crescimento rápido e as exigências sempre maiores de uma sociedade de consumo, onde as descobertas científicas, as inovações técnicas e a busca de ganhos tornam as coisas e os homens cada vez mais obsoletos. A mídia, cujo extraordinário desenvolvimento acompanhou esse movimento que é sua razão de ser, deriva do mesmo: produzindo, consumindo e reciclando cada vez mais rapidamente mais palavras e imagens.

Essas circunstâncias se expressariam, também, por intermédio da valorização da memória (voluntária, provocada, reconstruída), do patrimônio e das comemorações. Assim, conforme Hartog, a noção "lugar de memória" não poderia ser lida apenas de forma literal, mostrando-se sobretudo como instrumento de investigação e interpretação que remete a preocupações específicas de como escrever histórias nacionais na atualidade.

Penso, porém, que é em razão desses pontos que se torna pertinente relacionar o Museu Paulista a um "lugar de memória". Além do fato de que atualmente, por meio de várias iniciativas de pesquisa, núcleos de historiadores procuram caminhos historiográficos para escrever uma nova história da nação no Brasil, ${ }^{6}$ a expressão refere-se a locais de natureza material, funcional e simbólica em que o passado se encontra recuperado no presente. Designa manifestações da tradição nacional, feixes de representações e redutos da história/memória autenticada pela política e por produções historiográficas dos séculos XIX e XX. O lugar não é simplesmente dado, como observa Hartog; é construído e reconstruído sem cessar, podendo ser interpretado como encruzilhada onde se encontram ou deságuam diferentes caminhos de memória. Tanto Nora quanto Hartog ponderam, no entanto, que um "lugar de memória" pode perder sua destinação e reconhecem que, nos dias de hoje, os elos com esses lugares tornaram-se tênues, apontando para duas situações: primeiro, o distanciamento entre a história ensinada nas escolas e as expectativas de crianças e jovens motivados pelas experiências de aceleração do tempo que a cultura virtual pode proporcionar; e, segundo, os questionamentos acadêmicos a respeito das intenções e das maneiras como as histórias nacionais foram escritas.

Quanto a esse ponto, é importante lembrar algumas das observações de Dominique Poulot (2003), para quem contrariamente às aparências "os trabalhos de confirmação entre museus de História e historiografia ou ensino da História são bastante fracos".

O museu de história trabalha com o repertório das fontes do historiador, sanciona a emergência de novas curiosidades, tem seu próprio peso nas vicissitudes dos interesses sábios, enquanto vulgariza mais ou menos bem os conhecimentos eruditos junto aos visitantes [...]. Passa por momentos de maior intensidade ou 


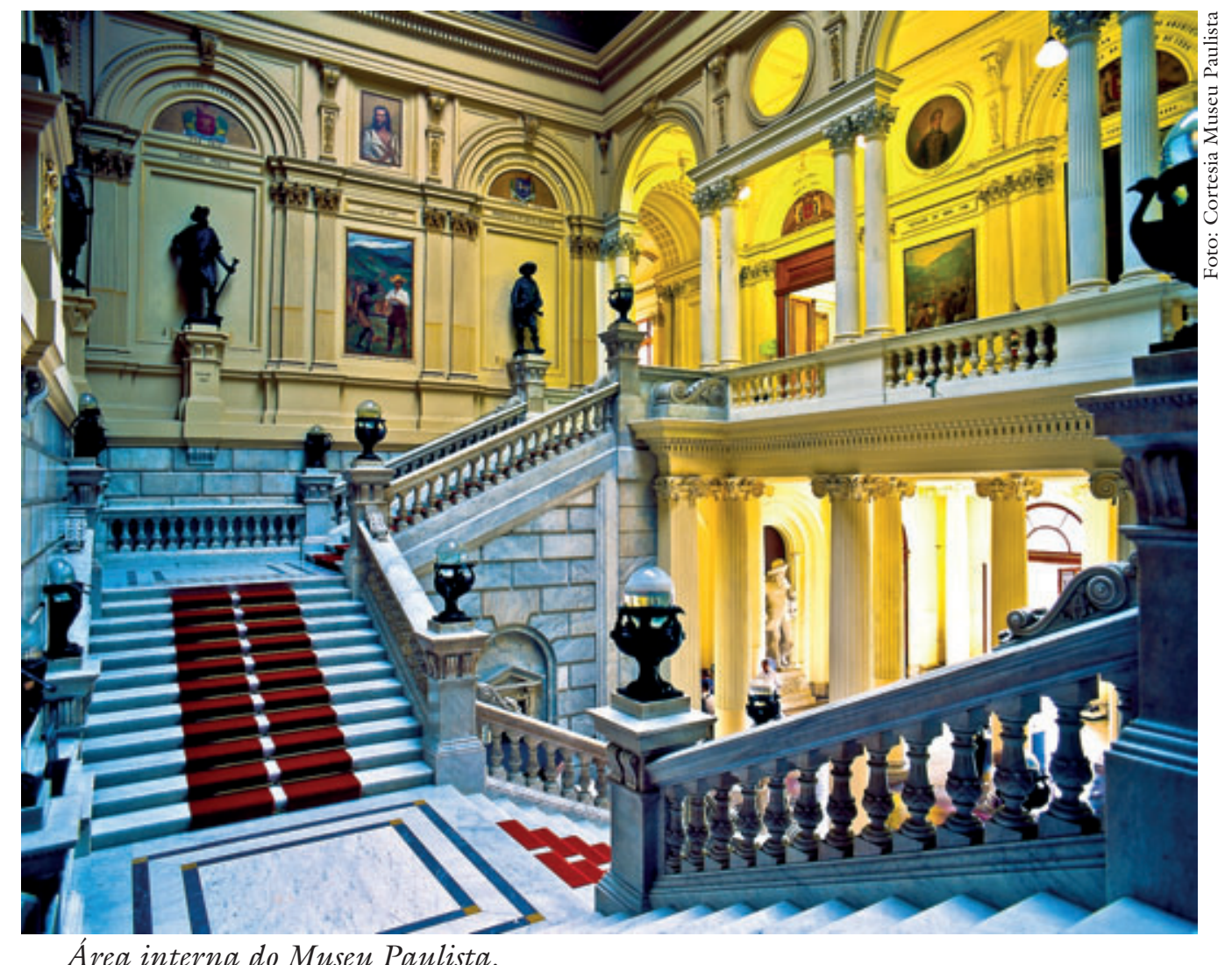

de fervor, quando o sentimento nacional o exige [...]. No entanto, o museu situa-se à margem da escrita da história, ao lado da compilação e da preservação de indícios do passado. Isolado da invenção intelectual dos escritos e dos reescritos, o museu também não constituiu uma matriz cultural, como a escola [...]. O espetáculo do museu ilustra [...] a discrepância entre a escrita da história e uma representação do passado capaz de evocar, de outro modo que o da memória, o reconhecimento do passado como tendo sido, embora já não mais seja [...].

O autor sublinha a posição atribuída aos museus de História, especialmente a partir da segunda metade do século XX, quando perderam densidade científica e foram sobrepujados pela produção intelectual ensejada, especialmente, pelas Universidades públicas. Mas, ao lado disso, Poulot reforça duas questões apontadas por Nora e Hartog: a de que a memória nacional e as tradições historiográficas que conformaram a história nacional nos séculos XIX e XX, contada nos manuais e expressa visualmente nos museus, se tornaram objetos de crítica e revisão pela pesquisa histórica mais recente; e a de que se instauraram rupturas entre as experiências culturais e sociais vivenciadas contemporaneamente e as representações do tempo e do passado inscritas nos ambientes dos museus de história.

Tais aspectos, no entanto, não esgotam a fisionomia matizada de instituições como o Museu Paulista. Reflexões de Paul Ricouer e Fernando Catroga (1999) sugerem que museus podem ser vistos, também, como locais para arti- 
culações entre memória e imaginação. Evocam um “objeto ausente” (ou uma presença ausente). Mas, se o "objeto ausente" pode ser ficcional para a imaginação, para a memória ele já não existe, embora tenha existido anteriormente. No caso dos Museus de História Nacional, e especialmente no percurso do Museu Paulista, esse traço adquire especial relevância em relação à decoração interna do edifício, pois pinturas, esculturas, imagens e objetos foram coletados e ali arranjados para reescrever a história brasileira e paulista, evocando acontecimentos e personagens, representando o passado e ensejando sua "visualização", como observou Stefan Bann (1994). Ou seja, tornam-se espaços de e para a imaginação do diversificado público que o frequenta e que necessariamente não compartilha as mesmas preocupações dos historiadores, ou tampouco observa o Museu pela mediação do lugar social, da prática investigativa e da escrita que caracterizam, segundo Michel de Certeau (2006), a operação historiográfica.

Assim, não se trata tão somente de indicar que o Museu abriga um imaginário no sentido mais literal do termo, ou seja, como conjunto de imagens visíveis e simbólicas. Trata-se de refletir sobre a complexidade de um ambiente que, ao mesmo tempo, mediatiza temporalidades, provoca tensões entre os desígnios acadêmicos e a "visualização" do passado e, ainda, confere tangibilidade ao universo contraditório e multifacetado das representações por meio das quais os sujeitos históricos estabelecem relações com o tempo e projetam interpretações sobre a sociedade à qual pertencem.

Talvez uma das razões do fascínio e do interesse que o Museu Paulista desperta, já que é um dos mais visitados do país, ${ }^{7}$ esteja no fato de reunir objetos e emblemas que permitem imaginar a vida e os costumes de tempos pretéritos. Além disso, o Museu oferece algo que não pode ser desconsiderado: a releitura, o que propicia a recriação e atualização de fragmentos de memórias, configurando-se como "lugar" do sentimento residual de continuidade. Como observou Ecléa Bosi (1994): “lembrar não é reviver, mas refazer, reconstruir, repensar, com imagens e idéias de hoje, as experiências do passado... a memória não é sonho, é trabalho...". Nesse sentido, cada visita ao Museu sugere uma experiência peculiar gerada pelas circunstâncias do momento, o que pode promover percepções diversas sobre a própria instituição e sobre o que ela reserva, assim como outras inferências sobre o passado ali representado.

\section{Desafios no presente}

Diante das demais unidades da Universidade de São Paulo, o Museu Paulista singulariza-se pelo exercício da curadoria, entendida como conjunto de atividades que orgânica e solidariamente são desenvolvidas em torno dos acervos. São elas: estudo e documentação; formação e ampliação de coleções, em consonância com as principais linhas de pesquisa institucionais; ${ }^{8}$ conservação e restauração. A esses procedimentos se associa a programação de ações educativas e culturais, o que abrange exposições, cursos de extensão em suas diferentes modalidades, seminários e demais eventos científicos e culturais, práticas vol- 
tadas para diferentes segmentos de público, desde o acadêmico até aquele que, de forma espontânea, frequenta o Museu. Ou seja, é a pesquisa em torno dos acervos e os conhecimentos produzidos por seu intermédio que fundamentam as diferentes atividades que o Museu realiza, o que envolve, também, disciplinas de graduação e de pós-graduação, bem como programas de iniciação científica e de pós-doutorado.

Nessa medida, visando à ampliação e ao aprofundamento do saber sobre a formação histórica da sociedade brasileira, assim como promovendo o enriquecimento da historiografia brasileira e paulista, o Museu desenvolve a pesquisa em duas dimensões complementares: formula e conserva coleções de diferentes tipologias, em sua área de especialidade, preparando-as para a reflexão crítica de pesquisadores e grupos de pesquisa brasileiros e estrangeiros; e, simultaneamente, busca, por meio de seu próprio corpo científico, realizar estudos circunstanciados sobre questões históricas para as quais possa contribuir do ponto de vista teórico e metodológico ou em termos de aplicabilidade em ações culturais e educativas.

A integração, entretanto, do Museu à Universidade e, particularmente, as modificações institucionais mais recentes deram maior visibilidade a tensões e ambiguidades que são inerentes à instituição. $\mathrm{O}$ fortalecimento da autonomia e o reconhecimento do papel de museus universitários na promoção de pesquisas multidisciplinares que agreguem esforços em torno do encaminhamento de questões centrais - como a qualificação do ensino universitário, a formulação de novas linhas de investigação e a abertura de programas de pós-graduação em áreas estratégicas - acabaram por evidenciar algumas limitações, a exemplo da carência de espaços físicos que permitam a adequada curadoria dos acervos e da necessária ampliação de recursos humanos, especialmente docentes.

Por sua vez, o perfil acadêmico da instituição convive contraditoriamente com demandas que exigem por vezes a "tradução" da pesquisa científica para outros patamares de compreensão. Beatriz Sarlo (2007) já havia apontado a coexistência, em um mesmo momento histórico, de diferentes "passados", construídos por intermédio de registros e preocupações de variada natureza. Ao lado da sensação de um tempo acelerado e da vertigem gerada pela rapidez com a qual patrimonização, rememoração e obsolescência se alternam no mundo contemporâneo, a história de corte acadêmico convive com sínteses históricas que visam atender ao mercado de consumo cultural e com reconstituições do passado pautadas nos trabalhos da memória. Esse entrelaçamento entre dimensões díspares e mesmo incongruentes do saber histórico é problema que diz respeito tanto à disciplina da História, de modo geral, quanto aos museus em particular, instituições que, operando acervos materiais, congregam funções científicas, documentais, educativas e culturais, interagindo cotidianamente com públicos de matizada feição, que esperam, procuram ou idealizam nesses espaços visões do e sobre o passado. 
Desse modo, é possível conjeturar que o interesse e a curiosidade despertados pelo Museu Paulista podem estar ancorados na possibilidade de a instituição oferecer uma singular concomitância entre novidade e permanência. O Museu seria um contraponto à vivência do tempo premente, marcado pela rapidez, pela sucessão veloz de eventos e situações e pela representação da ausência de durabilidade de referências.

Essa percepção também envolve os que militam nos museus. Está explicitada nas contradições entre o tempo necessário à pesquisa, capaz de acrescentar ao universo cultural e ao saber já existente um aporte inovador, e a demanda imediatista por eventos e exposições destinados à divulgação científica. Emerge particularmente no tocante às práticas de museificação e patrimonização.

Um dos horizontes do Museu reside na problematização e discussão da maneira como o conhecimento histórico foi e é produzido, dentro e fora da instituição. Isso representa questionar o estatuto dos documentos, as concepções e os procedimentos de saber que fundamentaram a seleção e sobrevivência das fontes, e especialmente o lugar ocupado pelo historiador na "teia" que envolve o movimento da história e a construção da memória, bem como as mediações entre acontecimentos e narrativas sobre os acontecimentos. A questão, como observou Poulot, diz respeito à fronteira muito tênue e movediça que separa o historiador debruçado sobre patrimônios recolhidos por gerações muito anteriores a ele e o historiador que se vê cotidianamente - como os que trabalham em museus - na posição de exercer o poder de determinar critérios e procedimentos de seleção e preservação de objetos, vestígios ou ruínas, a serem transformados em patrimônio no presente e no futuro. Tensão e ambiguidade marcam os vínculos e distanciamentos entre refletir sobre o patrimônio acumulado e ser agente do processo de patrimonização.

Mais do que superar, entretanto, essas complicadas situações, cuja raiz está na origem dos museus modernos, trata-se, sobretudo, de propor, neste momento de mudança institucional, que não se perca a oportunidade de o Museu Paulista ser o produtor de seu futuro, harmonizando a essência de ser museu à razão de ser da Universidade.

\section{Notas}

1 O primeiro Regimento do Museu Paulista data de 1894. Nele estava determinado que a instituição teria acervo de caráter sul-americano, destinando-se ao "estudo do reino animal, de sua história zoológica e da história natural e cultural do homem”. Instrumento para a instrução pública, seria núcleo de pesquisa cientifica sobre a "natureza do Brasil e do Estado de S. Paulo, em particular". Previa-se que, além das coleções de Ciências Naturais, haveria uma seção "destinada à Historia Nacional, especialmente dedicada a colecionar e arquivar documentos relativos ao período de nossa independência política". Previa-se, também, que, nas galerias e nos nichos do edifício, colocar-se-iam estátuas, bustos ou retratos a óleo de "cidadãos brasileiros" que tivessem prestado serviços 
relevantes ao Estado e que merecessem “a perpetuação de sua memória”. Ressaltava-se, igualmente, o lugar especial destinado ao painel de Pedro Américo, Independência ou Morte. Data da origem do Museu, portanto, a articulação entre ciência e história, concebida naquele momento como memória nacional. Ver: Decreto n.294, de 26 de julho de 1894, disponível no site <www.al.sp.gov.br>, acessado em julho de 2011.

2 Data de 1982 o Regimento dos Museus da USP, documento aprovado pelo Conselho Universitário, que procurou definir o papel dessas instituições na Universidade, particularmente do ponto de vista da pesquisa e da cultura e extensão, bem como em termos de intercâmbios entre si e com Departamentos e Faculdades afins. Em decorrência desses preceitos é que foi feito um novo Regimento interno para o Museu Paulista, aprovado em 1984.

3 Regimento do Museu Paulista, cf. Resolução USP n.4.393, de 8 de maio de 1997.

4 Resoluções USP n.5.900 e 5.901, de 23 de dezembro de 2010. Ambas alteram disposições do Estatuto e do Regimento Geral da Universidade, modificando o posicionamento dos Museus ao conferir-lhes maior autonomia acadêmica e administrativa.

5 A expressão "regime de historicidade" remete às reflexões desenvolvidas por François Hartog (2003) acerca do tempo e das diferentes maneiras como foi apropriado, compreendido e exercido no âmbito da escrita da História. Trata-se, simultaneamente, de instrumento heurístico e de categoria histórica de pensamento que permite interrogar, segundo o autor, os modos pelos quais, ao longo do tempo, configuraram-se articulações específicas entre passado, presente e futuro. Combatendo qualquer simplificação de ordem linear ou evolutiva, o que Hartog (2003) investiga são os fundamentos da relação da sociedade contemporânea com o tempo, o que denominou "presentismo", e seu entrelaçamento com a escrita da História.

6 Refiro-me, em particular, ao grupo de pesquisadores de Universidades fluminenses que compõe o Centro de Estudos do Oitocentos, liderado por José Murilo de Carvalho, Gladys Sabina Ribeiro, Lúcia Bastos, Lúcia Guimarães e Keila Grinberg, entre outros; e ao grupo de pesquisadores de Universidades paulistas que esteve reunido, entre 2004 e 2009, em torno do Projeto Temático "A fundação do Estado e da nação brasileiros, 1750/1850”, coordenado por István Jancsó, sediado na Universidade de São Paulo.

7 Dados compilados nos últimos dez anos mostram que a visitação ao Museu Paulista tem se mantido entre 300 e 350 mil pessoas/ano.

8 As três principais linhas de pesquisa, criadas durante a reformulação institucional dos anos de 1990, foram: Cotidiano e Sociedade; Universo do Trabalho; História do Imaginário. Atualmente, essas linhas se desdobraram, em razão dos trabalhos de organização física dos acervos e do aperfeiçoamento de instrumentos conceituais e metodológicos. Assim, destacam-se temáticas relacionadas à cultura visual, à história política, às relações de gênero, à história dos museus, à história da memória, à gestão de patrimônios, à configuração de espaços urbanos e cultura urbana, entre outras.

\section{Referências}

ALVES, A. M. de A. O Ipiranga apropriado. Ciência, política e poder. O Museu Paulista, 1893/1922. São Paulo: Humanitas, Programa de Pós-Graduação em História Social da USP, 2001. 
ANAIS DO MUSEU PAULISTA. História e Cultura Material. Nova Série, v.10/11, 2002-2003.

BANN, S. As invenções da história. Ensaios sobre a representação do passado. Trad. Flávia Villa-Boas. São Paulo: Editora Unesp, 1994.

BITTENCOURT, V. L. N. O Musen Paulista como lugar de escrita da História. Relatório de Pesquisa de Pós-Doutorado. Museu Paulista/Fapesp, 2010.

BOSI, E. Memória e Sociedade. Lembranças de velhos. 3.ed. São Paulo: Cia. das Letras, 1994.

BREFE, A. C. O Museu Paulista. Affonso de Taunay e a memória nacional. São Paulo: Unesp, Museu Paulista da USP, 2005.

CATrOGA, F. O céu da memória. Coimbra: Minerva, 1999.

CERTEAU, M. de. A escrita da História. 2.ed. Trad. M. L. Menezes. Rio de Janeiro: Forense Universitária, 2006.

ELIAS, M. J. Musen Paulista: memória e história. São Paulo, 1996. Tese (Doutorado) - Faculdade de Filosofia, Letras e Ciências Humanas, Universidade de São Paulo.

FEBVRE, L. Combats pour l'histoire. Paris: Armand Colin, 1965.

HARTOG, F. Tempo e História. Como escrever a história da França hoje? História Social, Campinas, n.3, p.127-54, 1996.

. Regimes d'historicité. Presentisme et expériences du temps. Paris: Seuil, 2003.

JANOTTI, M. de L. M. Os subversivos da República. São Paulo: Brasiliense, 1986.

KOSELLECK, R. Futuro Passado. Contribuição à semântica dos tempos históricos. Trad. W. P. Maas \& C. A. Prado. Rio de Janeiro: Contraponto, PUC-Rio, 2006.

MENESES, U. T. B. de. Do teatro da memória ao laboratório da história: a exposição museológica e o conhecimento histórico. Anais do Museu Paulista. História e Cultura Material. Nova Série, v.2, p.9-42, 1994.

MURARI, F. Mithistória. São Paulo: Humanitas; Fapesp, 1999.

NORA, P. Apresentação. In: (Dir). Les lieux des mémoires. Paris: Gallimard, 1984. v.1, p.VII-XLII.

OLIVEIRA, C. H. de S. O espetáculo do Ypiranga: mediações entre história e memória. São Paulo, 1999. Tese (Livre-Docência) - Museu Paulista da USP, Universidade de São Paulo.

OLIVEIRA, C. H. de S.; VALLADÃO, C. (Org.) O brado do Ipiranga. São Paulo: Edusp, 1999.

POULOT, D. Museu, nação, acervo. In: BITTENCOURT, J. N.; TOSTES, V.; BENCHETRIT, S. (Org.) História representada: o dilema dos museus. Trad. F. R. Willaume. Rio de Janeiro: Museu Histórico Nacional, 2003. p.25-62.

SARLO, B. Tempo passado: cultura da memória e guinada subjetiva. Trad. R. F. d'Aguiar. São Paulo: Cia. das Letras; Belo Horizonte: UFMG, 2007.

SOUZA, J. S. de. De casa a museu: 80 anos do Museu Republicano "Convenção de Itu”. Anais do Museu Paulista, v. 10/11, p.213-25, 2003.

TAUNAY, A. d'E. Guia da Seç̧ão Histórica do Museu Paulista. São Paulo: Imprensa Oficial, 1937. 
VAN PRAËT, M. Les musées d'histoire naturelle: savoirs, patrimoines et professionnalisation. In: BOUDIA, S. et al. (Dir) Patrimoine et communautés savantes. Rennes: Press Universitaires de Rennes, 2009. p.125-38.

VESENTINI, C. A. A teia do fato. Uma proposta de estudo sobre a memória histórica. São Paulo: Hucitec, Programa de Pós-Graduação em História Social da USP, 1997.

WITTER, J. S.; BARBUY, H. (Org.) Um Monumento no Ipiranga. São Paulo: Fiesp, Imprensa Oficial, 1997.

RESUMO - $\mathrm{O}$ artigo sublinha marcos do percurso do centenário Museu Paulista e discute alguns dos problemas e dilemas vividos atualmente pelos museus de História, particularizando os desafios de museus universitários.

Palavras-CHAVE: Museu Paulista, Museu universitário, Patrimônio, História, Memória. ABSTRACT - This article emphasizes milestones in the centenary history of Museu Paulista and discusses some of the problems and dilemmas faced nowadays by history museums, pointing out the challenges encountered by university museums.

KErWORDs: Museu Paulista, University museums, Patrimony, History, Memory.

Cecilia Helena de Salles Oliveira é diretora do Museu Paulista/USP.

@ - psalles@usp.br

Recebido em 15.8.2011 e aceito em 19.8.2011 